\title{
Genetic Algorithm Scaling for Compensation System Control in Micro Hydro/Solar Hybrid System for Rural Electrification
}

\author{
Biswajit Dhir \\ M. Tech Scholar \\ NRI Institute of Research \& Technology \\ Bhopal, India \\ biswajitdhir.1986@gmail.com
}

\author{
Mrs. Madhu Upadhyay \\ Head of Department \\ NRI Institute of Research \& Technology \\ Bhopal, India \\ madyant44@gmail.com
}

\begin{abstract}
Recent technologies have been focusing on power generation through renewable energy resources such as solar, wind, hydro etc. This paper focuses on development of a micro solar/hydro power generating resources feeding local loads. The compensation system derived for the small scale loading conditions at the load line was made using PI scaling Genetic Algorithm based control keeping the general architecture of the UPFC same. The results had depicted enhancement in the active power output, better reactive power compensation and reduction in THD levels of voltage and current at the load line.
\end{abstract}

Keywords: Solar Energy, Hybrid System, Pump, Hydropower.

\section{INTRODUCTION}

The micro-grid can be defined as an agglomeration of decentralized production units (DGs), normally connected to the power grid through electronic power devices (voltage source inverters). DG units can be built using unconventional energy sources such as fuel cells, wind turbines, hydroelectric and solar power. The microarray can be connected to the network or operate isolated from the network. The effects of power quality problems are significant when connecting the microgrid to the main grid and could become one of the most important areas of study. When a voltage imbalance is alarming, the semiconductor switch (CB), connected between the micro-grid and the public grid, opens to isolate the micro-grid.

Now-a-days, the researchers give their interests for the importance of a sustainable energy, especially it has been noticed that fossil fuel is costly and due to a large negative effect to the environment. Renewable energy presents the most suitable solution to get a great connection between renewable energy and sustainable development. The role of renewable energy has been defined as great significance for the global environmental concerns. Hydro-power is an efficient type example of renewable energy and its potential application to future power generation cannot be underestimated. Therefore, hydropower stations produce no air emissions but in most cases it has a bad effects on the water quality, wildlife habitats and prevent the fish migration but recently, new technology such as gravitational water vortex power system can solve this problem issue. Hydropower is currently the most secure, efficient and reliable source of renewable energy, based on more than a hundred years of professional experience [1]. Global hydroelectricity generation is increasing which representing $20 \%$ of world's electric generation in the last statistical data. Hydropower is produced from the extracted energy of water moving from higher to lower locations.

\section{LITERATURE REVIEW}

Dash R. et al. [1]this article introduces rapid industrialization and the demand for energy makes the distribution system more complicated. To solve this problem, a robust control system is being developed for the new micro-grid and smart grid concepts. These control systems are a complex structure that links renewable sources to traditional sources of energy production. The power quality problems resulting from the interconnection of the number of variable generation systems make it more dynamic and fault-oriented. 
Faisal R. Badal et al. [2]this article describes the usefulness of renewable energies in the world to generate electricity. Renewable energies significantly expand the electricity grid. Renewable energy sources are the driving force of a microgrid. The micro-grid is a small power grid with decentralized production units (DGs) connected in parallel. The challenges of integrating renewable energy sources and controlling micro-grids are described in this article.

NandKishor et al. [3]In this review article, the authors attempted to divide the research done so far into several sections based on the development of hydroelectric power plant models and their controller design. A significant amount of relevant research can be found on plant modeling, the design aspects of control methods and their study of performance.

Mohamed Walid et al. [4] Hydropower energy is one of the most suitable and efficient source of renewable energy which depends on more than century of experience for this issue. The power capacity and facility are two criteria required for the classification of hydropower plant. This paper gives a review of hydropower technologies and turbines; it is focusing on the categories and performance of hydro power systems and the most suitable turbines which can be used.

\section{OBJECTIVE}

The work has been focused on obtaining following key objectives:

- Designing of a solar system with UPFC controlled by PI controller for small scale generation as well as integrating it with the grid system in MATLAB /SIMULINK environment as the study is intended to focus on renewable energy resources for small scale consumption models

- Integration of the hydro power system with the solar PV system with grid integration driving small loads

- Designing of another compensating device and compare it with the standard UPFC compensator for active power output and reactive power output improvement in the system

- The compensating device control has to be designed with AI based genetic algorithm that is capable of adjusting the variation in input parameters for both solar and hydro systems and obtain a smooth voltage and current waveform for the load line.
- Reduction in the distortion level of the voltage output at the grid system is to be done by using the proposed optimizer.

\section{METHODOLOGY}

This study comprises with an analytical and numerical description of proposed algorithm for sentiment analysis of UPFC which is simulated to obtain the performance of the proposed algorithm.

The large-scale solar system is connected to grid via a converter and transformer. In order to improve the transient voltage stability of the large-scale solar system, reactive power compensation device UPFC is connected to grid. The compensator is being proposed for further enhancement in the output parameters like THD in voltage, THD in current and active power output.

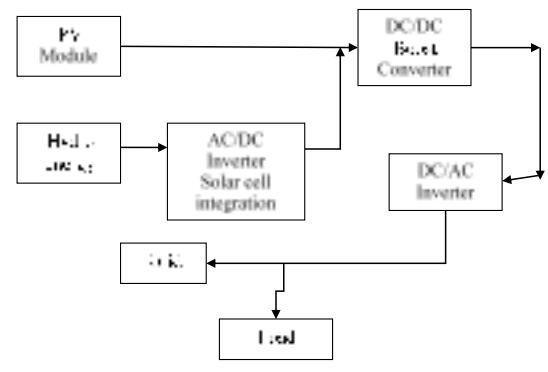

Figure 1: Hybrid energy system topology

As shown in Figure 1, the wind power generation system consists of PV system and AC/DC inverter and UPFC connected with the grid system.

\subsection{UPFC Working}

UPFC consists of two back to back GTO based voltage source converters (shunt and series) via a common DC link as shown in Figure 2. The main objective of series converter is to produce an ac voltage $\mathrm{Vc}$ of controllable magnitude and phase angle and inject this voltage at the fundamental frequency in series with the transmission line, exchanging the real and reactive powers at its ac terminals through the series connected transformers. The various equations implemented for 14 bus system has also been discussed. 


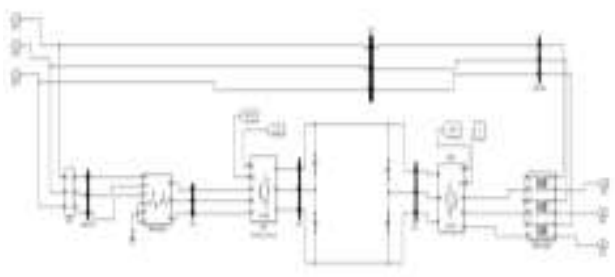

Figure 2. MATLB/SIMULINK Circuit of the Unified Power Flow Controller.

The shunt converter regulates the real power or it controls the capacitor's DC voltage by providing the required real power at the DC terminals. It also provides the voltage regulation of the shunt connected point through adjusting reactive power (generating or absorbing the reactive power). The two converters can generate or absorb the power independently without flowing through the DC link. Thus, UPFC can fulfill the functions of reactive shunt compensation, series compensation and phase shifting and meet multiple control objectives by adding the voltage $\mathrm{Vc}$ with appropriate amplitude and phase angle to the terminal voltage $\mathrm{Vu}$

The power system is composed of a synchronous machine connected to the grid via a transmission line. The UPFC is connected to the bus near the machine and its model is given as ideal transformer model shown in Figure 2. The power system model including UPFC is also shown in Figure 3.

To obtain the simplified block diagram, it is necessary to obtain the dynamic rotor equation and its parameters based on the parameters of Fig.4.8. The dynamic rotor equation is:

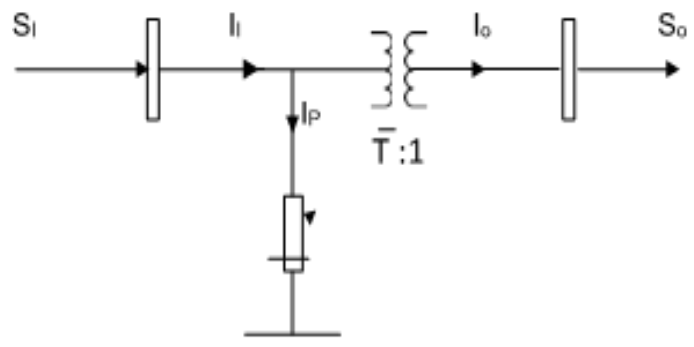

Figure 3 Ideal transformer model of UPFC

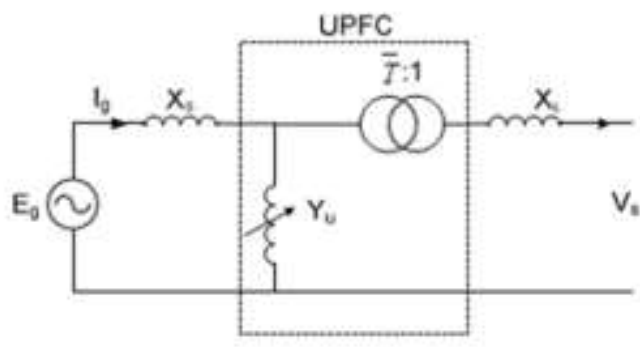

Figure 4. Power system model including UPFC

\subsection{Genetic algorithm for compensator designing}

Within the general framework of metaheuristic, the genetic algorithm approach comprises two steps: (i) obtaining an initial set of solutions, and (ii) implementing an improving search driven by specific rules in order to yield new solution sets. A genetic algorithm is a set-based method, i.e., in each step $\mathrm{k}$, the current state of the algorithm is represented by $\mathrm{Sk} \subseteq \mathrm{S}$, where $\mathrm{Sk}$ denotes the set of solutions in step k and $\mathrm{S}$ is the solution space.

For each solution set $\mathrm{Sk}$, a neighborhood $\mathrm{N}(\mathrm{Sk})$ is defined as all solutions resulting from the application of certain operators to the current solutions. A candidate solution set $\mathrm{C}$ $\subset \mathrm{N}(\mathrm{Sk})$ is selected from the neighborhood $\mathrm{N}(\mathrm{Sk})$ of the current solution set. The selected candidate solution set is subsequently evaluated through the calculation or estimation of the performance of the candidate solutions. Based on this evaluation, candidate solutions yield the solution set of the next step $\mathrm{Sk}+1$. This process is repeated until a convergence criterion is met. Figure 5 presents the general structure of a genetic algorithm under a metaheuristic framework.

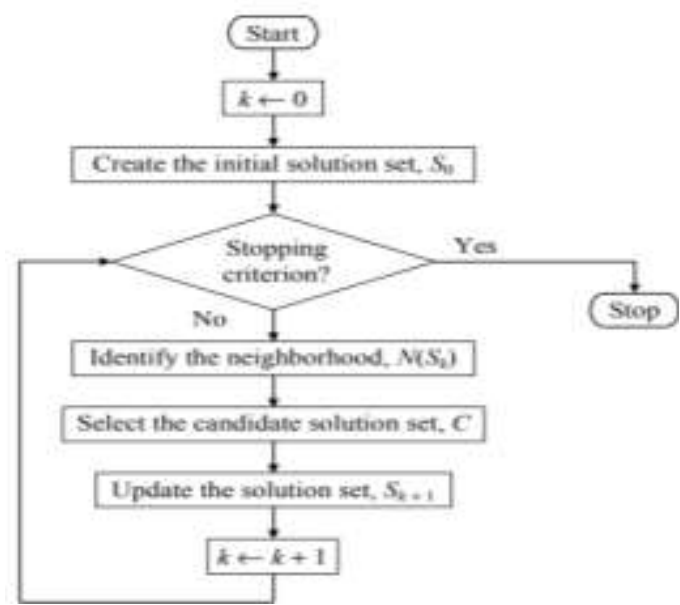

Figure 5 Genetic Algorithm performance flow chart The proposed genetic algorithm designed specifically for the power factor correction and reactive power balancing is initiated by generating randomly an initial population of binary coded individuals (V, I, frequency and phase), where each individual represents a possible solution of power system parameters (Active and reactive power). Each individual of current population is evaluated for $\mathrm{J}$ and a basis for the biased selection process is then established. The objective values obtained for each individual are mapped into fitness values through a ranking process. The higher the individual 's fitness is, the higher is its chance to pass-on 
genetic information to successive generations. The next generation populated with offspring, obtained from selected parents. The entire population is replaced by offsprings using crossover and mutation in standard genetic algorithm, whereas in proposed Genetic Algorithm the parents are selected on the basis of fitness value and the best parent chromosome is retained, comparing the fitness values of both the parents and the children, the best stings will go for the next generations.

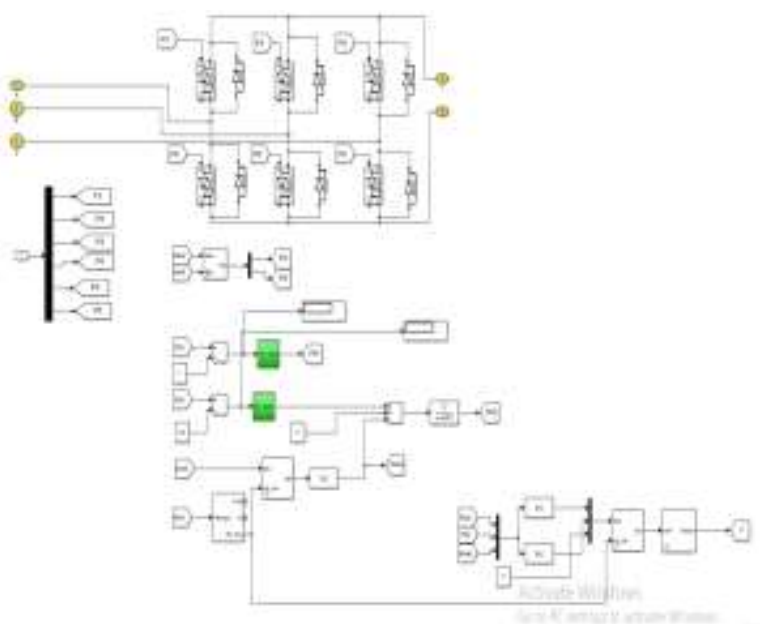

Figure 6 Proposed PI scaling Genetic algorithm based PWM generation for power optimization control for the compensator

\section{RESULTS}

Electricity requirement is increasing day by day all over the world. The power generation of electrical energy to fulfill the power requirement is mainly done with the use of fossil fuels such as oil, coal, and gas. The conventional scheme of power generation may cause depletion of the fossil fuel and degradation of environment. This field is henceforth chosen for our work on these resources.

The work focuses on analysis of a solar energy system by implementing it in MATLAB/SIMULINK software. The system is made to get integrated with the grid system also in order to enhance its efficiency. The distortion level has been calculated for both voltage and current waveforms neglecting the sudden transient at the starting of system. In this paper, a system is proposed in which hydro and solar based hybrid power generation system is connected with the utility grid. The load driving capacity for the hybrid system is approximately $20 \mathrm{KW}$. The limitation with the hydro system is its poor voltage and frequency regulation. Therefore, a reliable technique is required to maintain constant voltage and frequency irrespective of the load and load types The chapter here discusses the solar/hydro energy system in the following two cases.

Case 1: Solar PV system with grid integration having UPFC driven by standard PI controllers

Case 2: Solar PV/hydro hybrid system with grid integration having UPFC driven by standard PI controllers

Case 3: Hybrid Energy system with proposed PI scaling Genetic algorithm based PWM generation for power optimization control for the compensator

The DC output voltage form the solar energy system is fed to the inverter for its DC/AC conversion. The solar panel has been modelled with PV arrays having 10 cells connected in each series with 40 parallel branches that together give out the DC output from the system. The variable illumination of 1000 lux is provided along with varying temperature of $25^{\circ} \mathrm{C}$ .This output is and further sent to the inverter for its $\mathrm{AC}$ conversion.

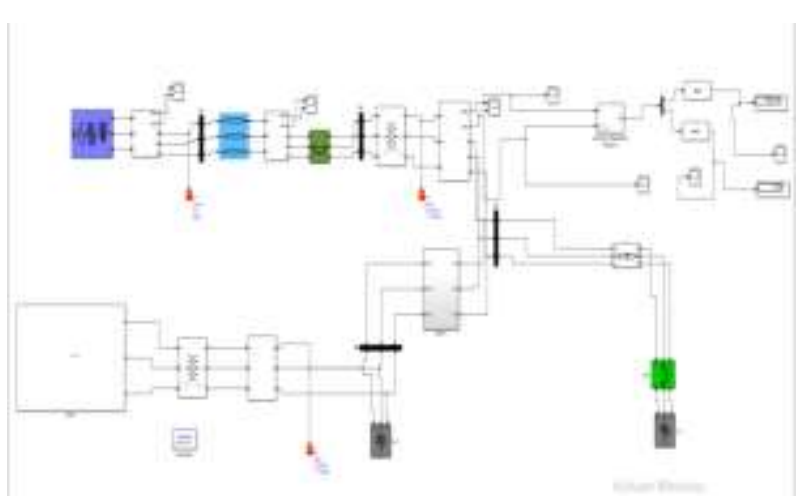

Figure 7 Matlab/SIMULINK model of the grid connected PV system with UPFC

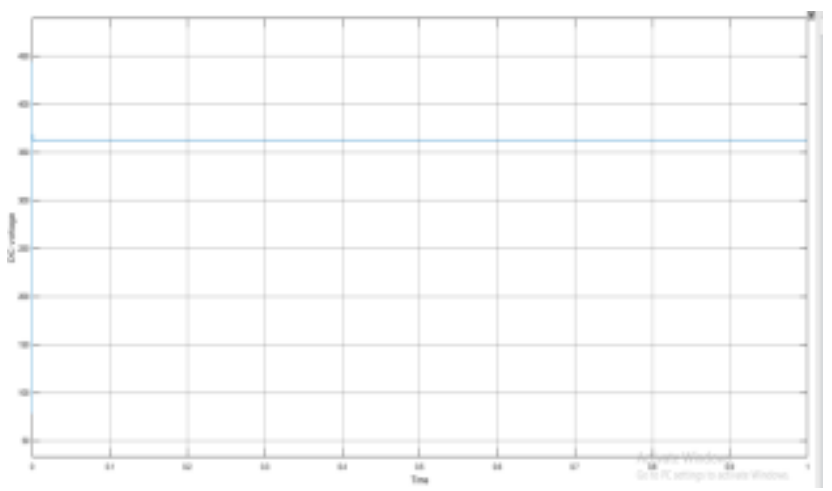

Figure 8 DC output voltage from the grid connected solar PV system

Case 1: Solar PV system with grid integration having UPFC driven by standard PI controllers 
The system in this case is modeled with solar energy with UPFC having converters driven by PI controller which is then further integrated with the grid. Further the voltage current, active power and reactive power waveforms have been analyzed.

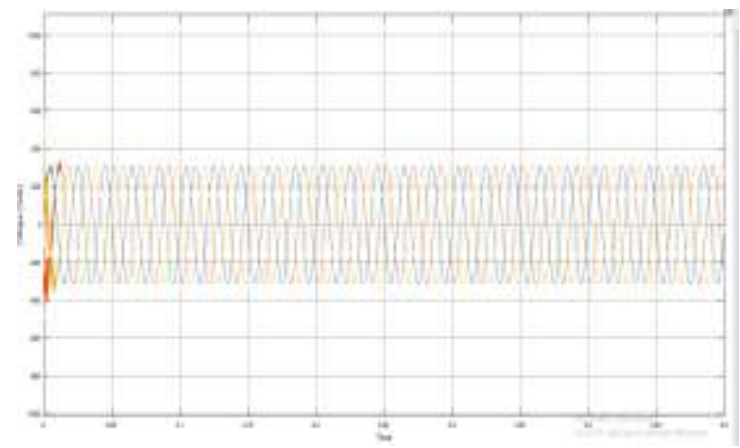

Figure 9 Voltage in transmission line in the grid connected system with UPFC having PI controlled electronic converters

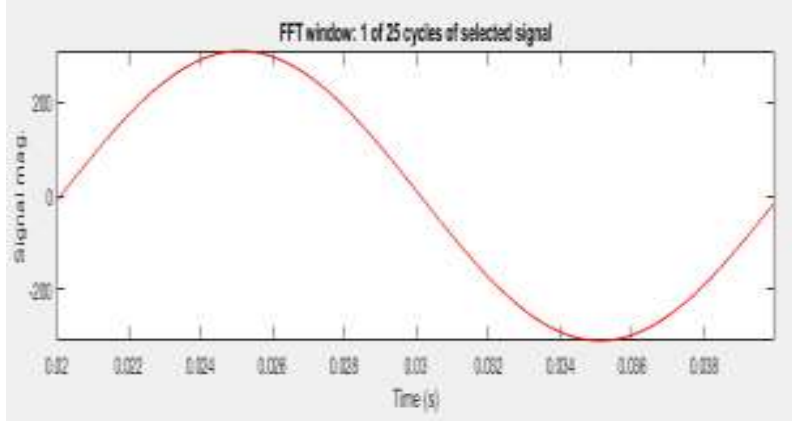

Figure $10 \mathrm{FFT}$ analysis of Voltage in transmission line in the grid connected system with UPFC having PI controlled electronic converters

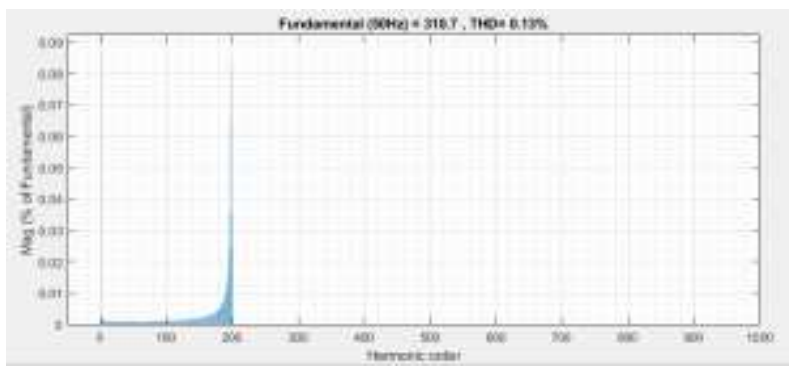

Figure 11 THD\% of Voltage in transmission line in the grid connected system with UPFC having PI controlled electronic converters

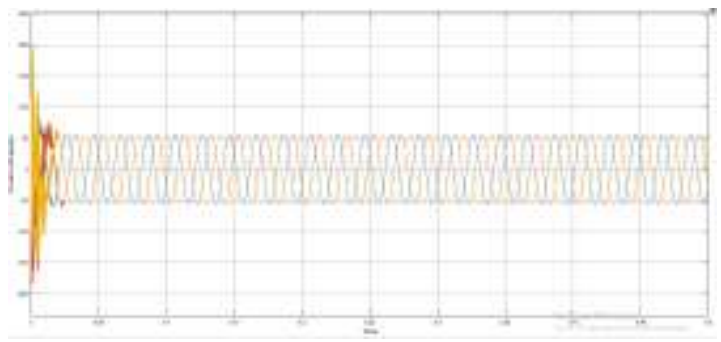

Figure 12 Current in line in the grid connected system with UPFC having PI controlled electronic converters

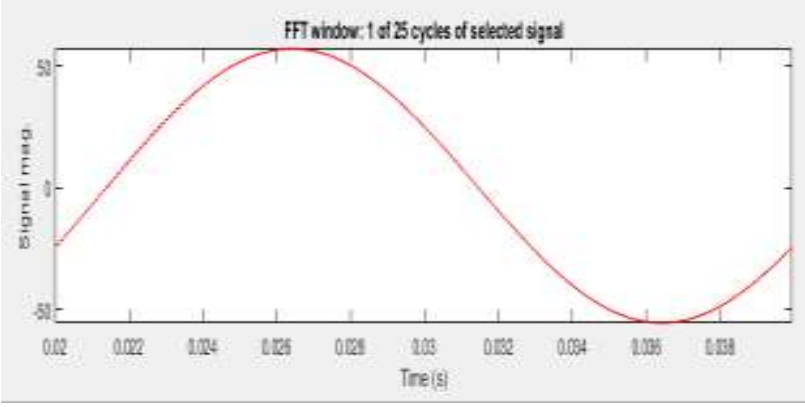

Figure 13 FFT Analysis of Current in line in the grid connected system with UPFC having PI controlled electronic converters

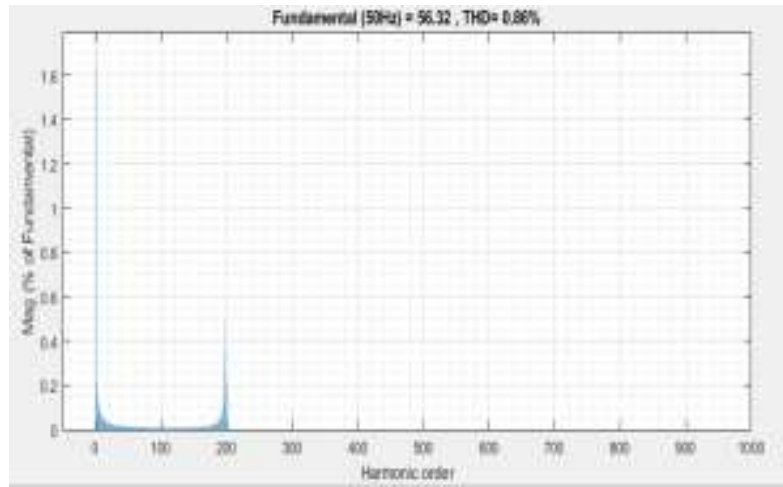

Figure 14 THD\% of Current in line in the grid connected system with UPFC having PI controlled electronic converters

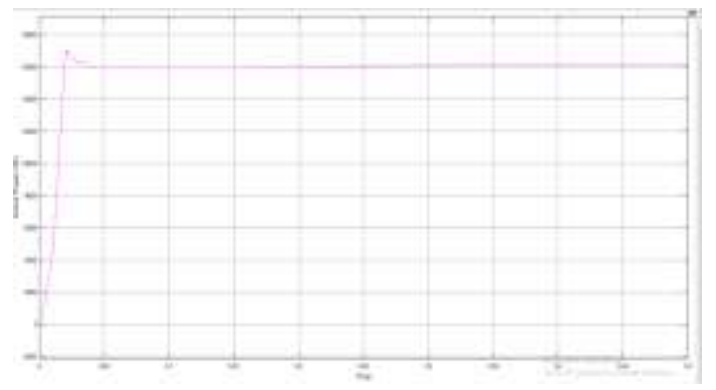

Figure 15 power available in the grid connected system with UPFC having PI controlled electronic converters 


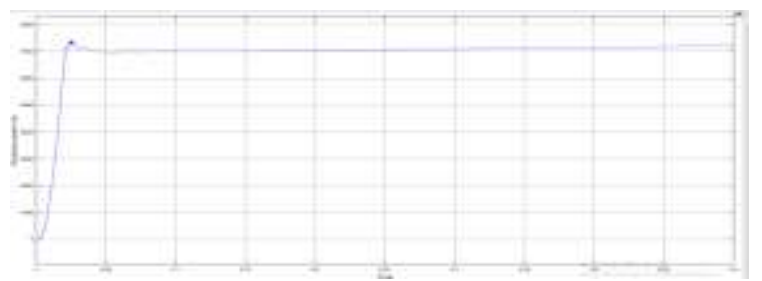

Figure 16 Reactive power available in the grid connected system with UPFC having PI controlled electronic converters

The above waveforms shows the voltage output, current output, active power output, and reactive power in the system having UPFC in line, driven by PI controlled converters. It is concluded that the voltage output is coming to be approximately 310 volts. The current was found o be approximately 56.32 Ampere with active power output as $16130 \mathrm{~W}$ and reactive power output as 7204Var.

Case 2: Solar PV/hydro hybrid system with grid integration having UPFC driven by standard PI controllers

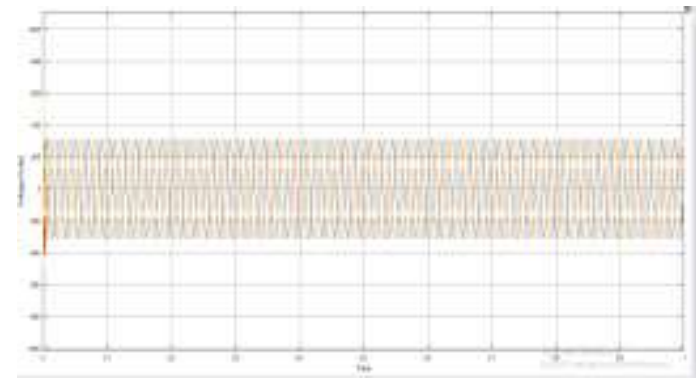

Figure 17 Voltage in transmission line in the grid connected hybrid system with UPFC having PI controlled electronic converters

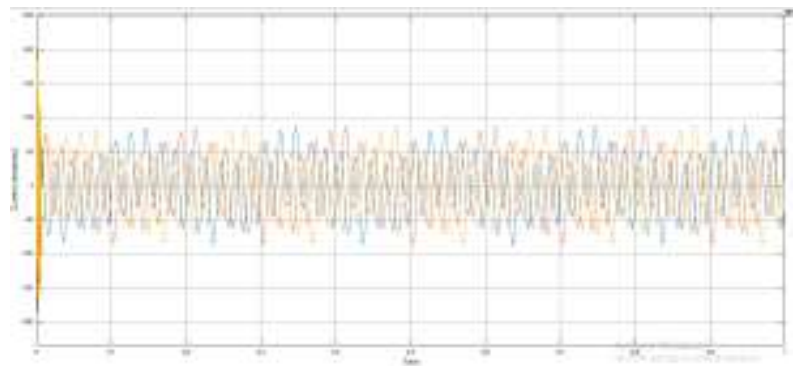

Figure 18 Current in transmission line in the grid connected hybrid system with UPFC having PI controlled electronic converters

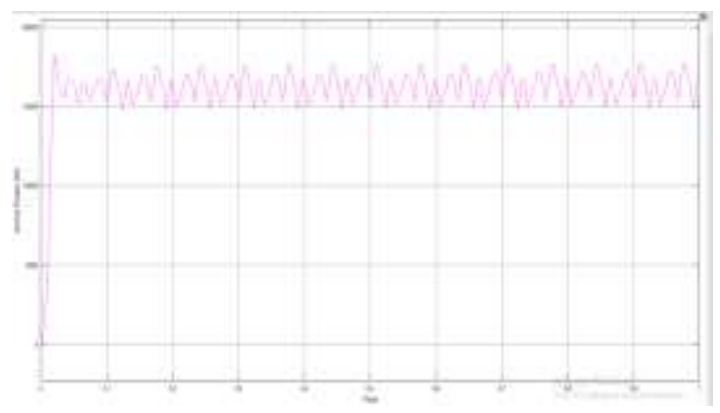

Figure 19 Active Power in transmission line in the grid connected hybrid system with UPFC having PI controlled electronic converters

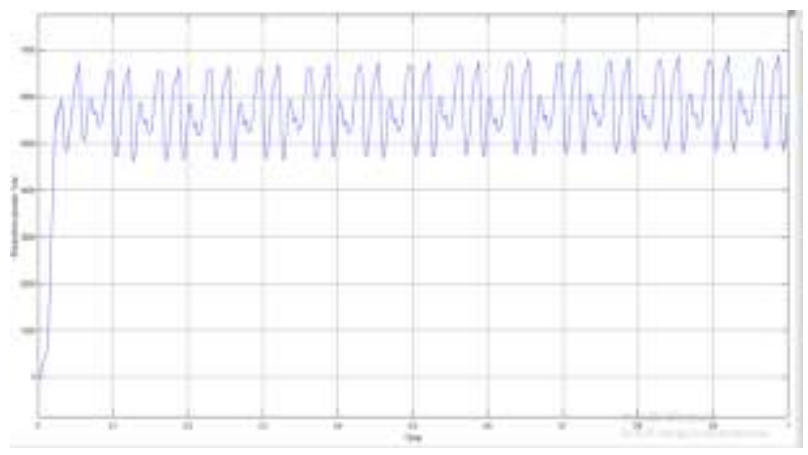

Figure 20 Reactive power in transmission line in the grid connected hybrid system with UPFC having PI controlled electronic converters

The dynamic nature of the hydro power system has been studied to produce instability in the load line after it is being connected with the solar PV system. The standard UPFC design with the PI controllers was not seen to adapt itself to varying output parameters. The hence the micro hydropower system with hybrid solar energy were redesigned with an optimizing controller for compensating device.

Case 3: Hybrid Energy system with proposed PI scaling Genetic algorithm based PWM generation for power optimization control for the compensator

The system in this case is modeled with solar energy with power flow compensator having two converters driven PI scaling Genetic algorithm based PWM generation for power optimization control which is then further integrated with the grid. Further the voltage current, active power and reactive power waveforms have been analyzed. 


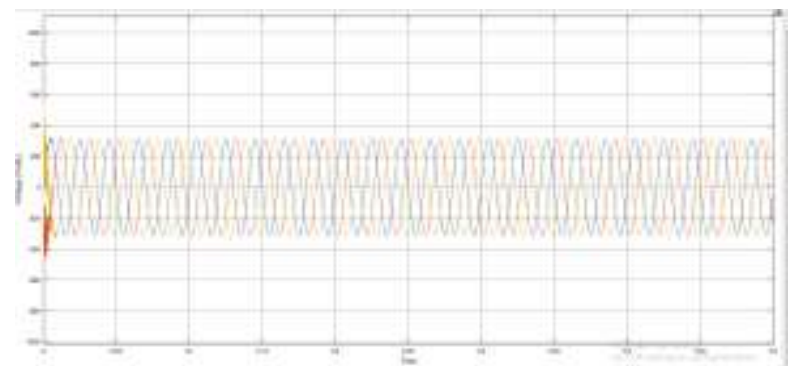

Figure 21 Voltage in the transmission line in Hybrid Energy system with proposed PI scaling Genetic algorithm based compensator

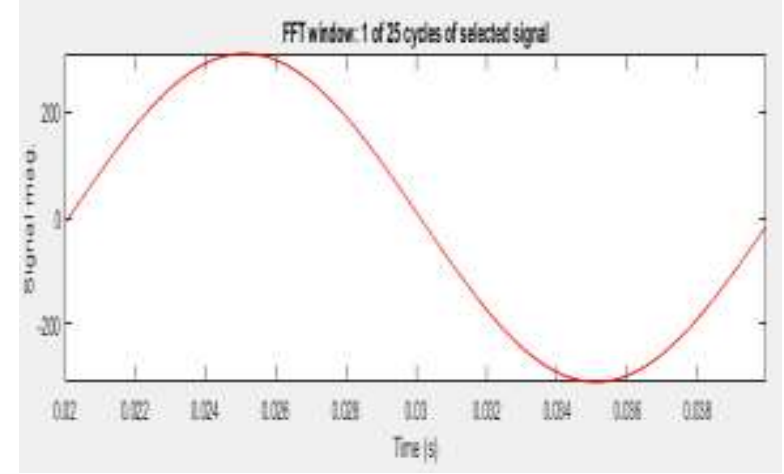

Figure 22 FFT analysis of Voltage in Hybrid Energy system with proposed PI scaling Genetic algorithm based compensator

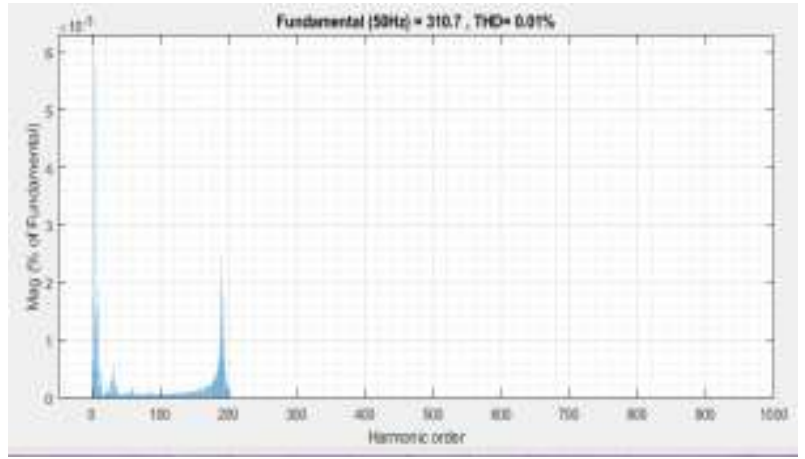

Figure 23: THD \% of Voltage in Hybrid Energy system with proposed PI scaling Genetic algorithm based compensator

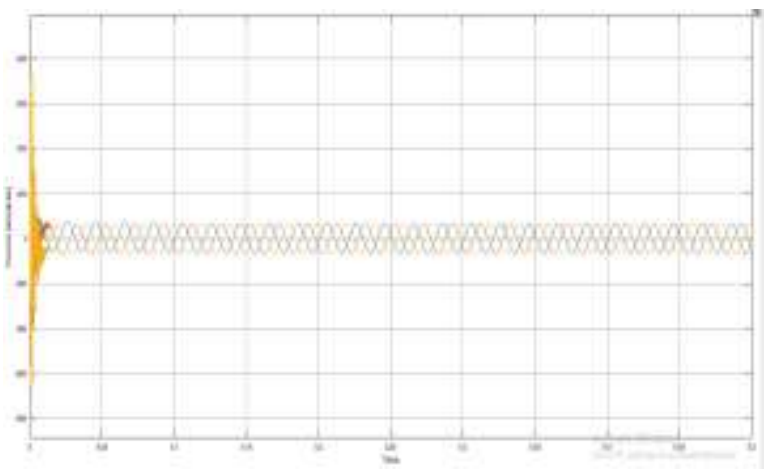

Figure 24 Current in Hybrid Energy system with proposed PI scaling Genetic algorithm based compensator

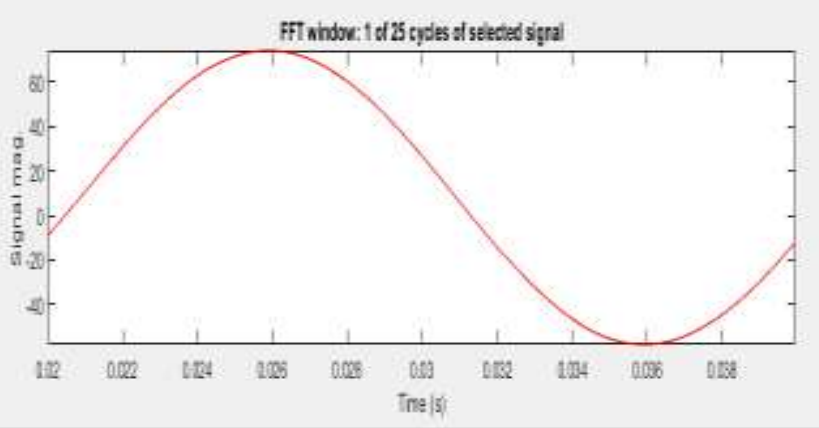

Figure 25 FFT analysis of Current in Hybrid Energy system with proposed PI scaling Genetic algorithm based compensator

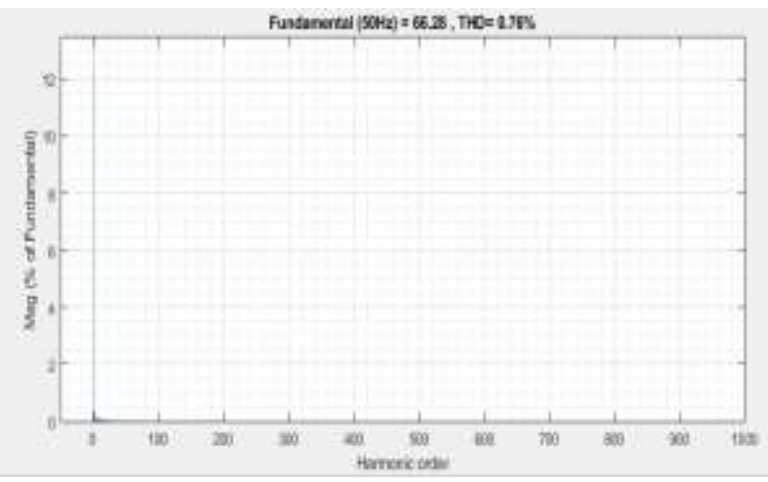

Figure 26 THD\% of Current in Hybrid Energy system with proposed PI scaling Genetic algorithm based compensator 


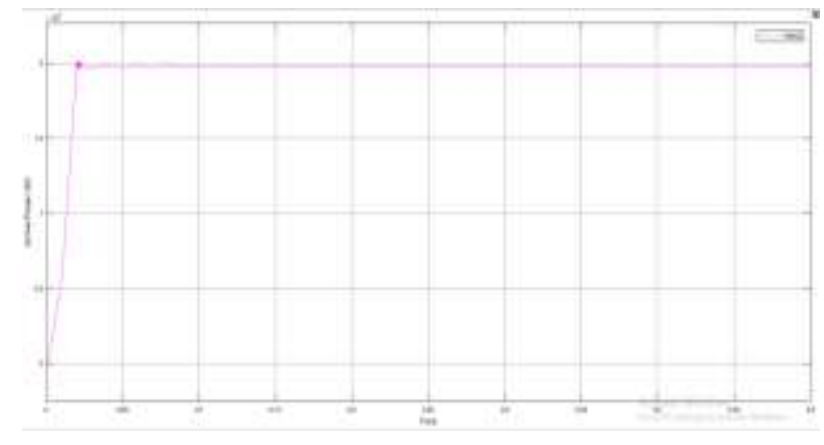

Figure 27: Active power available in Hybrid Energy system with proposed PI scaling Genetic algorithm based compensator

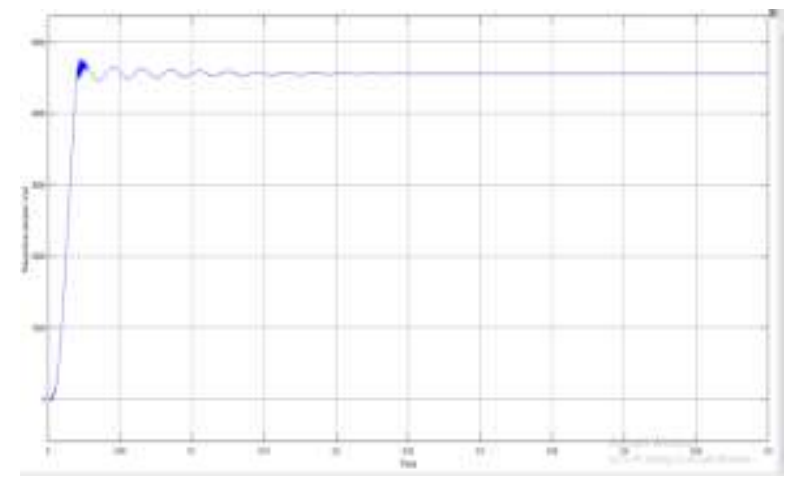

Figure 28: power available in Hybrid Energy system with proposed PI scaling Genetic algorithm based compensator

The above waveforms shows the voltage output, current output, active power output, and reactive power in Hybrid Energy system with proposed PI scaling Genetic algorithm based compensator. It is concluded that the voltage output is coming to be approximately 310 volts. The current was found o be approximately 66.28 Ampere with active power output as $19760 \mathrm{~W}$ and reactive power output as 4559Var.

$$
\text { VI. VALIDATION: }
$$

The UPFC modeled with contrived crow search based algorithm is expected to produce better results as compared to the UPFC with PI controlled converters

\begin{tabular}{|c|l|c|c|}
\hline S.no & Parameters & $\begin{array}{c}\text { system with } \\
\text { UPFC having } \\
\text { PI controlled } \\
\text { electronic } \\
\text { converters }\end{array}$ & $\begin{array}{c}\text { Hybrid Energy } \\
\text { system with } \\
\text { proposed PI scaling } \\
\text { Genetic algorithm } \\
\text { based compensator }\end{array}$ \\
\hline 1 & $\begin{array}{l}\text { Active power } \\
\text { output }\end{array}$ & $16130 \mathrm{~W}$ & $19760 \mathrm{~W}$ \\
\hline 2 & Voltage Output & $310 \mathrm{~V}$ & $310 \mathrm{~V}$ \\
\hline 3 & $\begin{array}{l}\text { THD\% in voltage } \\
\text { THD in } \\
\text { current }\end{array}$ & $0.13 \%$ & $0.01 \%$ \\
\hline
\end{tabular}

\begin{tabular}{|c|l|c|c|}
\hline 5 & $\begin{array}{l}\text { Reactive Power } \\
\text { output }\end{array}$ & 7204Var & 4559Var \\
\hline 6 & Power Factor & 0.92 & 0.96 \\
\hline
\end{tabular}

The above results show the comparative values of all the parameters. The active power output available has been enhanced from approximately $16130 \mathrm{~W}$ at the UPFC with PI controlled converters at the bus in the system to $19760 \mathrm{~W}$ Hybrid Energy system with proposed PI scaling Genetic algorithm based compensator which is also connected with the grid. The reactive power output in the transmission line was studied to be reduced making it more stable from 7204 Var to 4559 Var.

\section{CONCLUSION}

The work here presents a solar based renewable energy system in MATLAB/SIMULINK environment for analysis. The solar energy system was derived in connection with the grid making having UPFC in the load line. The system was further made hybrid with the micro hydro technology. The standard UPFC design was seen to be unable to stabilize the system and hence have designed Hybrid Energy system with proposed PI scaling Genetic algorithm based compensator which is a part of artificial intelligence. Following main conclusions were drawn:

- The active power output from the system has enhanced to $19760 \mathrm{~W}$ in the system having compensator designed using the GA based control for the converter regulated from the proposed controller that is constrained crow search algorithm from 16130 in system having UPFC regulated from PI controllers.

- The active power output from the system has enhanced to $19760 \mathrm{~W}$ in the system having compensator designed using the GA based control for the converter regulated from the proposed controller that is constrained crow search algorithm from 16130 in system having UPFC regulated from PI controllers.

- The metaheuristic GA algorithm optimized in a manner that the distortion level in the output electrical parameters is also reduced The voltage output distortion level from the solar energy system was found to be $0.01 \%$ which is less than $0.13 \%$ of the system having UPFC regulated from PI controllers. 
- The current distortion level has also come down to $0.76 \%$ using the proposed controller from the $0.86 \%$ in the solar system.

- The system is also integrated with the grid energy system. The line voltage being maintained to 310 Volts. The reactive power output has also reduced. The algorithm has proven to be more effective in the compensating the reactive power as well.

The above description concludes that the solar system is made efficient for driving the loads having enhanced active power output at its terminal. The voltage available has been made less distorted and the THD level in current output has also came down.

\subsection{Future Scope}

Research and development is a non-stopping process. For any research work carried out, there is always a possibility for better chances of improvement and lot many avenues opened for further work. Following aspects are identified for further scope of research work.

1. The present work can be extended to power system with generalized TCSC, STATCOM and Interline Power Flow Controller (IPFC).

2. The system investigated has been limited up to a two renewable based power system. It would be desirable to extend the proposed approach for larger and more realistic systems.

3. The present work can be extended for STATCOM and SSSC with energy storage such as battery Energy Storage System (BESS) and Superconducting Magnetic Storage (SMSS) for enhancing power system stability.

4. Stability issues for a distribution network with different types of distributed generation sources and FACTS devices could be examined and FACTS-based controllers could be designed for improving the stability in presence of different types of distributed generations.

5. Different strategies could be tested and implemented in an attempt to achieve a less time consuming process and gain better understanding of heuristic optimization techniques applicability to various power system phenomena

\section{REFERENCES}

[1] Dash R., Sarat Chandra Swain "Effective Power quality improvement using Dynamic Activate compensation system with
Renewable grid interfaced sources" Ain Shams Engineering Journal, 2018.

[2] Faisal R. Badal, Purnima Das, Subrata K. Sarker "A survey on control issues in renewable energy integration and microgrid" Protection and Control of Modern Power Systems Volume 4, Article number: 82019.

[3] Nand Kishor, R.P. Saini "A review on hydropower plant models and control" Renewable and Sustainable Energy Reviews 11(5):776-796 · June 2007

[4] Mohamed Walid, Omar Yakob "Hydro Power and Turbine Systems Reviews" May 2015.

[5] Chiyembekezo S. Kaunda, Cuthbert Z. Kimambo "Hydropower in the Context of Sustainable Energy Supply: A Review of Technologies and Challenges" International Scholarly Research Notices / 2012.

[6] Ioannis Kougias, GeorgeAggidis "Analysis of emerging technologies in the hydropower sector" Renewable and Sustainable Energy Reviews, Volume 113, October 2019, 109257.

[7] Bhupendra Singh Niranjan, Dashrath Kumar "Power Quality Improvement by Using UPQC in Wind Energy Conversion System" International Journal of Advanced Research in Electrical, Electronics and Instrumentation Engineering, Vol. 8, Issue 3, March 2019.

[8] Mohit Bajaj, Amit Kumar Singh “An analytic hierarchy processbased novel approach for benchmarking the power quality performance of grid-integrated renewable energy systems" 102, pages1153-1173(2020).

[9] Chandra S. Rao Menda, Nagarju Subuddi "Performance Evaluation of Static Compensation for Grid Connected System for Power Quality Improvement Features" Volume 02, issue 11 November 2013.

[10] Priya M, Vivekananda Sibal T "power quality improvement of multifunctional grid connected inverter with renewable system" International Journal of Electrical Engineering \&amp; Technology (IJEET). 